\title{
Two cases of aplastic anaemia associated with tumours of the thymus
}

\author{
R. D. S. BARNES ${ }^{1}$ AND P. O'GORMAN ${ }^{2}$ \\ From the Group Laboratory, Lewisham Hospital, London
}

SYNOPSIS Two cases are presented in which aplastic anaemia was associated with thymus tumours. In Case 1 the patient had a pancytopenic aplastic anaemia and was treated with A.C.T.H. The. marrow showed regeneration at necropsy. The thymoma in this case was unusual as there was thymic regression with fat replacement which may have been related to A.C.T.H. Case 2 was initially of ain pure red cell anaemia with but little tendency to produce a leucocytosis in response to infection and $\oplus$ was found at necropsy to have a lymphoepithelioma of the thymus. Previously reported cases are 5 reviewed and the role of A.C.T.H. in treatment is discussed.

The simultaneous occurrence of aplastic anaemia and a thymus tumour is uncommon, and, although 35 cases have now been recorded, the interest associated with the concurrence of these two diseases has encouraged us to present two further cases.

CASE 1 J. O'N., an interior decorator aged 41, was admitted on 21 April 1960 with a four-month history of dyspnoea, bruising, epistaxis, and a rash. The patient had no significant previous illness nor had he been exposed to benzene or its derivatives.

Examination showed pallor and generalized purpura, the liver was palpable, and Hess's test was positive. The blood count was $\mathrm{Hb} \mathrm{34 \%}(5.0$ g. \%), P.C.V. $18.5 \%$, reticulocytes less than $1 \%$, and W.B.C. 1,600 per c.mm. (672 neutrophils, 32 eosinophils, 864 lymphocytes, and 32 monocytes). A platelet count showed 19,000 per c.mm. The direct Coombs test was negative. Sternal marrow fragments were hypocellular and free cells were scanty, showing depression of all series. A diagnosis of aplastic anaemia was made and confirmed by iliac crest biopsy.

The patient was treated with fresh blood and platelet concentrated transfusions and 160 i.u. of the zinc suspension A.C.T.H. intramuscularly every third day, from 19 May 1960 until death, as part of a trial of this preparation which will be reported separately by the present authors. Deterioration was progressive and there was no real evidence that the aplasia was responding. The reticulocyte count was always less than $1 \%$ and the platelet count could only be maintained above 10,000 per c.mm. by transfusion. On 15 July the patient developed pneumonia, a pyrexia of $102^{\circ} \mathrm{F}$., peripheral circulatory failure, and fresh purpura and died on $17 \mathrm{July}$. Urinary 17-hydroxycorticosteroid levels which were $48 \cdot 4$,

'Now at Guy's Hospital, S.E.1.

Now at Brook General Hospital, S.E.18.

Received for publication 12 September 1961.
40.4 , and $17.4 \mathrm{mg}$./day after the first injection of A.C.T.H. $\vec{C}$ fell to $12 \cdot 4,10 \cdot 6$, and $5 \cdot 2 \mathrm{mg}$./day on the three days beforeo death, despite increased dosage of A.C.T.H.

At necropsy, there were petechiae and ecchymoses allo over the skin and throughout the intestine. A non-s encapsulated, lobulated, fatty tumour of the thymus weighing $63 \mathrm{~g}$., was attached to, but had not invaded, then pericardium, great vessels, and trachea. The cut surfacep was a uniform pale pink and was slightly greasy, showing no areas of haemorrhage or necrosis. The sternal andō vertebral bone marrow was pale and fatty. Both adrena $\beta$ glands were enlarged and there was some haemorrhage into their substance.

Sections of the thymus gland (Fig. 1) showed the tissue to be predominantly fatty, with bundles of oedematouso connective tissue, in which were scattered lymphocytes and large cells with clear or reticular nuclei, and areas of persistent thymic tissue consisting mainly of small lymphocytes, in some of which Hassall's corpuscles could3 be seen. The bone marrow was very fatty, but areas of intense cellular proliferation were present, the predominant cells being haemocytoblasts (Fig. 2). Com $\frac{7}{O}$ parison with the original marrow (Fig. 3) showed a dramatic alteration in haemopoiesis. The spleen and 0 lymph nodes showed lymphoid regression due to A.C.T.H: The adrenals were congested, the sinusoids dilated and engorged with areas of haemorrhage. There was hydropic w degeneration of the cells of both cortex and medulla.

CASE 2 Mrs. L. H., aged 42, was admitted in April $1951 \frac{0}{\square}$ with confluent bronchopneumonia and a pyrexia of $101 \cdot 4^{\circ} \mathrm{F}$. She had previously had nine attacks of pneu=monia, treated with penicillin and sulphonamides. She had had no contact with benzene or its derivatives. The्্চ total W.B.C. count was 7,000 per c.mm. $\left(2,660\right.$ neutro- $\frac{\varrho}{1}$ phils, 140 eosinophils, 4,060 lymphocytes, and $140 \mathrm{~B}$ monocytes). A chest radiograph showed interstitiato fibrosis and at screening a lobulated mass was seen in the 

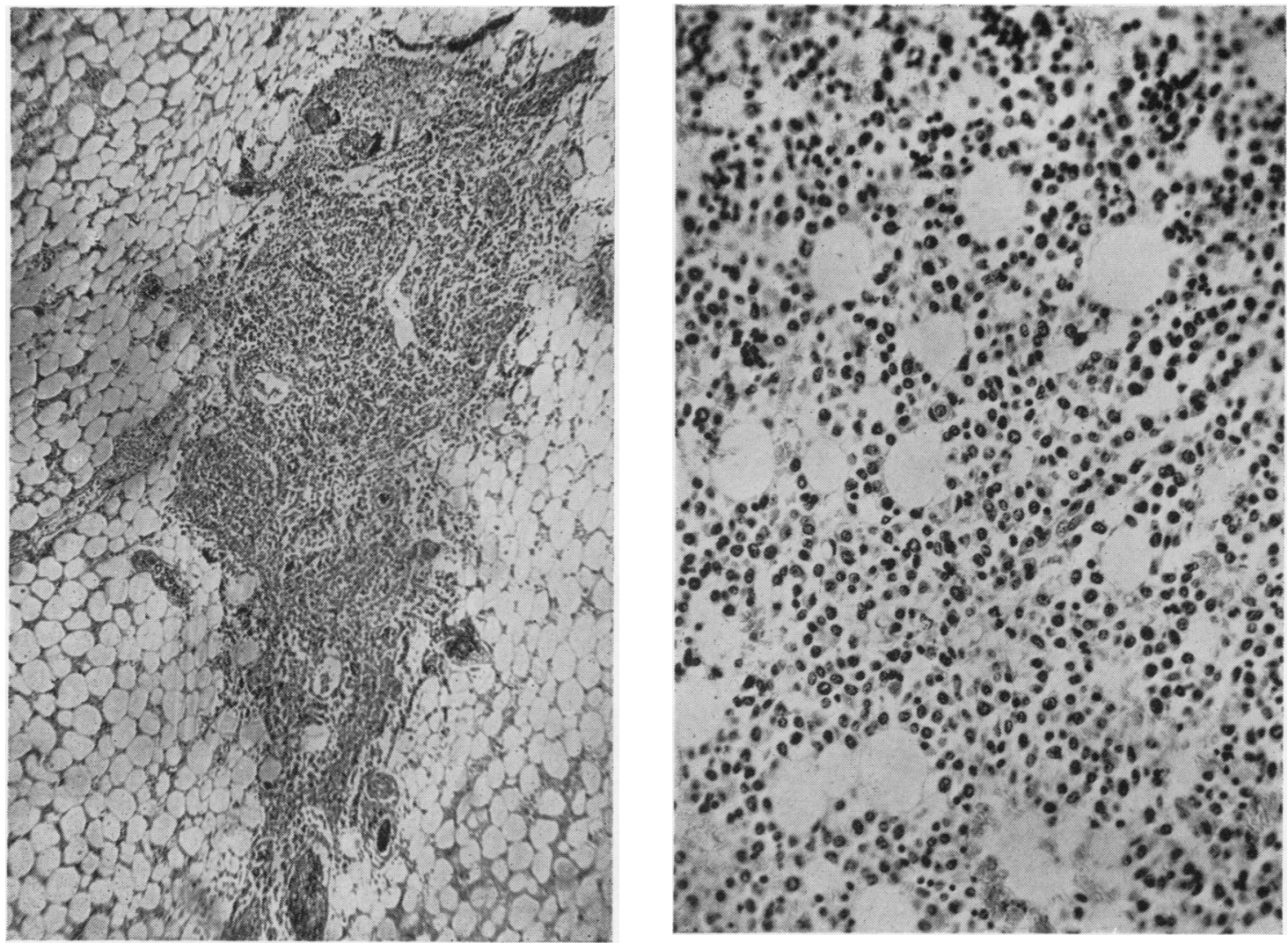

FIG. 1

FIG. 2

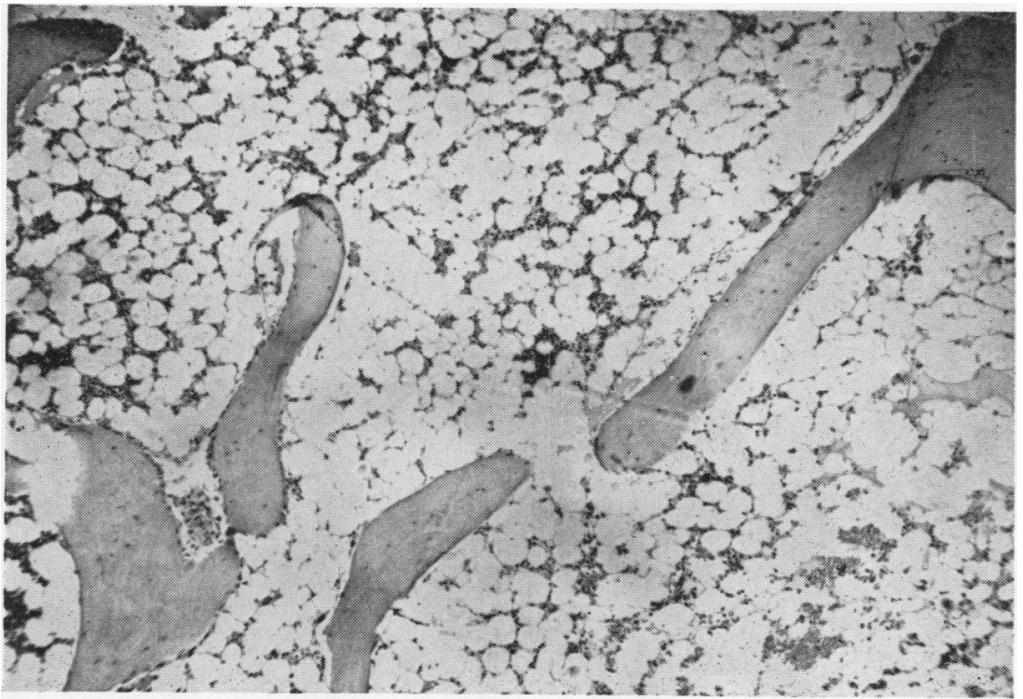

FIG. 1. Case 1. Section of thymus tumour, showing areas of persistent thymic tissue despite widespread fatty infiltration $(\times 50)$.

FIG. 2. Case 1. Section of bone marrow at necropsy, showing areas of active haemocytoblastic proliferation $(\times 250)$.

FIG. 3. Case 1. Section of bone marrow before treatment, showing severe hypoplasia $(\times 50)$.

FIG. 3 
anterior mediastinum. She was treated with penicillin, sulphonamide, and also chloramphenicol to a total dosage of $24.5 \mathrm{~g}$. The pneumonia resolved but after discharge she had several attacks of bronchitis and was readmitted in June 1951 with a further chest infection which responded to tetracycline. Haemoglobin was then $54 \%(8.0 \mathrm{~g} . \%)$ and in the absence of haemorrhage fell in a week to $44 \%(6.5 \mathrm{~g} . \%)$ with a R.B.C. count of $2,090,000$ per c.mm. and a W.B.C. count of 6,500 per c.mm. (2,860 neutrophils, 260 eosinophils, 130 basophils, 130 monocytes, 3,120 lymphocytes). $H$. influenzae was isolated from the sputum and after evaluation of the sensitivity to streptomycin this drug was given, with marked improvement in the patient's general and pulmonary condition, for a period of 14 days. One month after admission her blood count was: $\mathrm{Hb} 41 \%(6 \cdot 1 \mathrm{~g} . \%)$, R.B.C. $2,050,000$ per c.mm., P.C.V. $18 \cdot 5 \%$, M.C.V. 77.5 c $\mu$., M.C.H. $30.5 \gamma \gamma$, M.C.H.C. $33 \%$, M.C.D. $6.7 \mu$, and W.B.C. 8,500 per c.mm. $(1,615$ neutrophils, 680 eosinophils, 5,695 lymphocytes, and 510 monocytes). The total serum proteins were $5.95 \mathrm{~g}$. per $100 \mathrm{ml}$. $(5.0 \mathrm{~g}$. albumin and $0.95 \mathrm{~g}$. globulin). One week later, the haemoglobin was $28 \%(4 \cdot 1 \mathrm{~g} . \%)$ and the reticulocyte count only $0.6 \%$. Sternal marrow then showed 'no

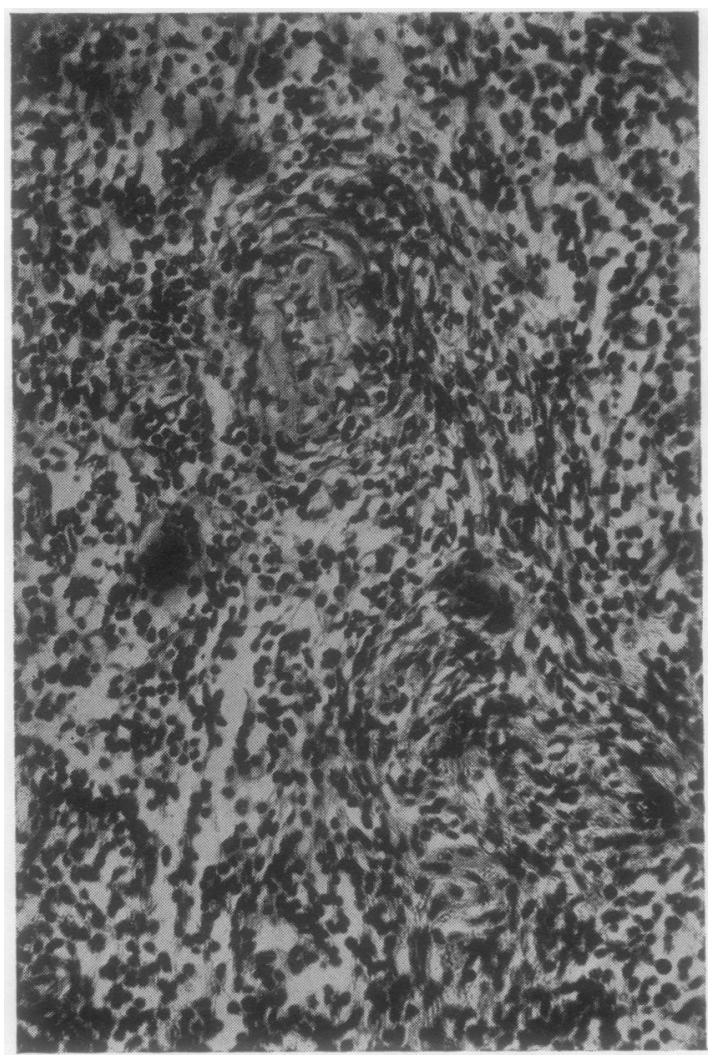

FIG. 4. Case 2. Section of the lymphoepithelioma of the thymus, showing lobules of pleomorphic cells $(\times 250)$.

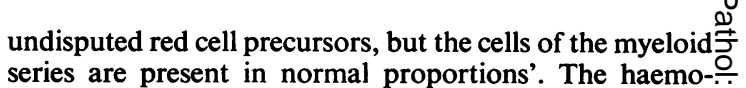
globin continued to fall despite transfusions; neither $\Rightarrow$ vitamin $\mathrm{B}_{12}$, folic acid, A.C.T.H. (25 mg. eight hourly for 15 days) nor cortisone (100 mg. daily for 19 days) hado any effect on the anaemia.

A further attack of bronchopneumonia in September 1951 responded to penicillin and streptomycin although the W.B.C. remained at 7,500 per c.mm. with only 5,229 neutrophils.

क

For the next year Mrs. L. H. was maintained with $\vec{\circ}$ monthly blood transfusions and occasional courses of penicillin, but in November 1952 she noted spontaneousc bruising. Her platelet count was then 140,000 per c.mm and W.B.C. only 1,400 per c.mm. In December 1952 she died in a further attack of bronchopneumonia, her- $\vec{G}$ W.B.C. count being only 1,700 per c.mm.

At necropsy (Dr. M. O. Skelton) there was a tumour $9 \times 4 \mathrm{~cm}$. in the upper anterior mediastinum, which was? hard and fibrous and on section had the appearance of thyroid tissue. There was emphysema and bronchitis and many small firm nodules were palpable in both lungs. $\overrightarrow{-}$ The histology of the mediastinal mass revealed lobules of pleomorphic cells with small hyperchromatic nuclei, among which Hassall's corpuscles could be seen (Fig. 4). $\overrightarrow{0}$ The lobules were separated by bands of fibrous tissue and there was a diffuse lymphocytic infiltration. The marrow showed a moderate number of white cell precursors ando lymphocytes, but very few primitive erythroid cells. The lung showed emphysema with congestion, the nodules being areas of old organizing pneumonic consolidation, with superimposed acute inflammation.

\section{DISCUSSION}

The two cases now presented are similar to most of the 32 cases reviewed or recorded by Havard and Bodley Scott (1960). Our two cases and the threes other cases presented by Wintrobe (1951), Couespel, Gaillard, and Vaillant (1960), and Freeman (1960) respectively bring the total number of occasionso where this syndrome has been recognized and re 3 corded to thirty-seven.

Twenty of the previously recorded 35 cases, as did our Case 2, showed a pure red cell aplasia. The remainder had leucopenia, thrombocytopenia, and $\bar{N}$ or complete aplasia, as in our Case 1 . In addition the second patient had a hypoglobulinaemia similaro to the cases described by Ross, Finch, Street, and Strieder (1954), by Ramos (1956), and by Lambie? Burrows, and Sommers (1957), an association firsto reported by Good (1954); its significance is uncertain The tumour in Case 2 was a relatively poorly? differentiated lymphoepithelioma (Willis, 1953) of low malignancy and was histologically similar to. many of those reported. However, the histologs of the tumour in Case 1 is most unusual. The appear $\frac{\mathbb{D}}{2}$ ance is not unlike that of the regressing thymus at puberty, but the age of the patient and the् 
weight of the tumour make this unlikely. On the other hand, it is very similar to those lipomata of the thymus recorded by Shillitoe and Goodyear (1960) and by Dunn and Frkovich (1956). None of the 18 cases reviewed by the former authors had associated aplastic anaemia and were larger asymptomatic tumours. If, in fact, the tumour is a lipoma, then this is the first recorded case of aplastic anaemia associated with a thymic lipoma. The aetiology of this syndrome is uncertain. The occurrence of the tumour several years before the anaemia in the cases described by Humphreys and Southworth (1945), Chalmers and Boheimer (1954), Ross et al. (1954), Ramos (1956), Bayrd and Bernatz (1957), Lambie et al. (1957), Clarkson and Prockop (1958), Jacobs, Hutter, Pool, and Ley (1959), and Kurrein (1959) makes improbable the suggestion (Ross et al., 1954) that anaemia is a factor in the development of the tumour. Chalmers and Boheimer (1954) suggested a common endocrinological aetiology because the eventual remission of the anaemia in their two cases followed A.C.T.H. Our findings in Case 1 support this theory. The normal adult thymus atrophies as a response to steroid therapy (Selye, 1949), and this fact associated with the findings in this patient of lymphoid regression in the thymus, spleen, and lymph nodes, plus the obvious marrow regeneration, led us to consider the possibility of regression of a true thymoma associated with remission of the aplastic anaemia, resulting from A.C.T.H. therapy. Chalmers and Boheimer's two patients received A.C.T.H., but also underwent splenectomy and thymectomy. The possibility that A.C.T.H. may be an effective therapy for the thymoma as well as for the aplastic anaemia is only a working hypothesis which we propose to test at the earliest opportunity.

These considerations suggest that the thymoma may be responsible for the anaemia, and this is supported by Havard and Bodley Scott's (1960) statement in their review that no patient has been recorded as deriving benefit from steroids or haematinic drugs before removal or irradiation of the thymus, although since then Couespel et al. have recorded a case that showed some improvement in the blood count before thymectomy while being treated with steroids alone. The results of such treatment, however, are inconsistent. Of 16 patients submitted to thymectomy (Humphreys and Southworth, 1945; Barquet Chediak, Fuste, and Vazquez Rosales, 1953; Chalmers and Boheimer, 1954; Ross et al., 1954; Bakker, 1954; Bayrd and Bernatz, 1957; Lambie et al., 1957; Clarkson and Prockop, 1958; Jacobs et al., 1959; Parry, Kilpatrick, and Hardisty, 1959; Couespel et al., 1960; Freeman, 1960), two died post-operatively and only nine patients showed any improvement. In the cases described by Humphreys and Southworth (1945), Chediak et al., (1953), Bakker, (1954), and Jacobs et al. (1959) the response was immediate, while in one case the improvement was delayed (Ross et al., 1954). In the case recorded by Parry et al. (1959), steroids were also required, and in the two cases of Chalmers and Boheimer (1954) splenectomy was also performed. Four patients (Rakojević and Hahn, 1935; Green, 1958; Jacobs et al., 1959; Havard and Bodley Scott, 1960) have been treated with irradiation of the mediastinum, without improvement; two of these later received steroids and one of them (Havard and Bodley Scott, 1960) had a complete remission.

Adrenocorticotrophic hormone may have been a factor in the ultimate collapse of Case 1. The presence of a systemic infection, a platelet count less than 10,000 per c.mm., and low steroid excretion in the last three days of life may be related to the haemorrhagic and degenerative state of the adrenals at necropsy, although the changes do not amount to a frank adrenal apoplexy. These changes may represent a type of acute adrenal insufficiency similar to the Friderichsen-Waterhouse syndrome, and in retrospect, it might have been better to have treated this terminal phase with hydrocortisone as replacement therapy rather than to have increased the stimulation of the failing adrenals with more A.C.T.H.

In Case 1 the treatment of the anaemia was of little benefit, the patient having received various haematinics and short courses of cortisone and A.C.T.H. without avail, although it is possible that had hormone therapy been continued it might have been beneficial. We do not believe that the initial course of chloramphenicol given to this patient is related to the aplastic anaemia. Scott, Cartwright, and Wintrobe (1959) discussed this relationship and concluded that severe marrow depression is most likely following prolonged use of the drug. Hodgkinson (1954) noted that aplastic anaemia usually followed large doses and the majority of his patients had taken two to four times the normal maximum dose of 2 to $3 \mathrm{~g}$./day. Our patient received $24.5 \mathrm{~g}$. over seven days, and although chloramphenicol cannot be excluded as an aetiological factor with absolute certainty, the presenting pure red cell anaemia associated with the thymoma and the incidental finding of hypoglobulinaemia make it most unlikely.

We should like to thank Dr. S. Llewellyn-Smith and Dr. L. V. Roberts for permission to reproduce details of their cases, Dr. M. O. Skelton for allowing us to quote his necropsy report in Case 2, and Dr. E. N. Allott and Dr. C. A. Holman for their advice and encouragement. 
REFERENCES

Bakker, P. M. (1954). Ned. T. Geneesk., 98, 386.

Barquet Chediak, A., Fuste, R., and Vazquez Rosales, G. (1953). Arch. hosp. univ. (Havana), 5, 27.

Bayrd, E. D., and Bernatz, P. E. (1957). J. Amer. med. Ass., 163, 723.

Chalmers, J. N. M., and Boheimer, K. (1954). Brit. med. J., 2, 1514.

Clarkson, B., and Prockop, D. J. (1958). New Engl. J. Med., 259, 253.

Couespel, R., Gaillard, J. A., and Vaillant, G. (1960). J. franc. Méd. Chir. thor., 14, 617.

Dunn, B. H., and Frkovich, G. (1956). Amer. J. Path., 32, 41.

Freeman, Z. (1960). Brit. med. J., 1, 1390.

Good, R. A. (1954). Bull. Univ. Minn. Hosp., 26, 1

Green, P. (1958). Canad. med. Ass. J., 78, 419.

Havard, C. W. H., and Bodley Scott, R. (1960). Brit. J. Haemat., 6, 178.

Hodgkinson, R. (1954). Lancet, 1, 285.

Humphreys, G. H., and Southworth, H. (1945). Amer. J. med. Sci., 210, 501 .
Jacobs, E. M., Hutter, R. V. P., Pool, J. L., and Ley, A. B. (1959). Cancer (Philad.), 12, 47.

Kurrein, F. (1959). J. clin. Path., $12,319$.

Lambie, A. T., Burrows, B. A., and Sommers, S. C. (1957). Amer. J. clin. Path., $27,444$.

Parry, E. H. O., Kilpatrick, G. S., and Hardisty, R. M. (1959). Brit. med. J., 1, 1154 .

Rakojevic, S., and Hahn, A. (1935). Strahlentherapie, 53, 90.

Ramos, A. J. (1956). J. Amer. med. Ass., 160, 1317.

Ross, J. F., Finch, S. C., Street, R. B. Jr., and Strieder, J. W. (1954). Blood, 9, 935.

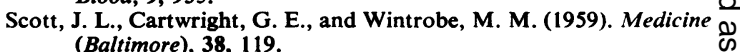

Selye, H. (1949). Textbook of Endocrinology, 2nd ed. Acta Endo- crinologica Inc., Montreal.

Shillitoe, A. J., and Goodyear, J. E. (1960). J. clin. Path., 13, 297.

Willis, R. A. (1953). Pathology of Tumours, 2nd ed. Butterworth, $\vec{\omega}$ London.

Wintrobe, M. M. (1951). Clinical Hematology, 3rd ed. Kimpton, London; Lea and Febiger, Philadelphia.

\section{The March 1962 Issue}

\section{THE MARCH 1962 ISSUE CONTAINS THE FOLLOWING PAPERS}

Phosphatase activity in the limb bones of monkeys (Lagothrix humboldti) with hyperparathyroidism GRACE M. JEFFREE

Skeletal pigmentation due to tetracycline H. B. HILTON

The fine structure of chordoma with particular reference to the physaliphorous cell I. FRIEDMANN, D. F. N. HARRISON, and E. S. BIRD

Subcutaneous phycomycetosis J. B. LYNCH and A. D. HUSBAND

Congenital defect of the pericardium E. G. H. BRUNING

Exfoliated 'myeloma cells' in the urine of a case of multiple myelomatosis C. M. PROWSE and T. E. BLECHER

A survey of staphylococcal infections in group 9 hospitals JOAN M. READ and E. YENSON

Cross-infection with Serratia marcescens GEOFFREY TAYLOR and P. M. KEANE

A latex particle precipitation test in the diagnosis of thyroid disease J. R. PHILP, D. M. WEIR, A. E. STUART, and W. J. IRVINE

A comparison of tests for thyroglobulin antibody J. R. RAWSTRON and C. P. FARTHING
Improved rapid methods for the determination of iron content and binding capacity of serum R. N. BEALE, J. O. BOSTROM, and R. F. TAYLOR

Red cell aggregation in dextrose solutions J. H. $\stackrel{\mathscr{Q}}{\overparen{Q}}$ JONES, G. S. KILPATRICK, and E. H. FRANKS The ABO and Rhesus blood groups in Perthes' disease J. MALCOLM CAMERON and MARIAN M. IZATT An improved dinitrosalicylic acid method for determing blood and cerebrospinal fluid sugar levels A. F. MOHUN and I. J. Y. COOK

The determination of copper in biological materials $\frac{\sigma}{3}$ by flame spectrophotometry G. E. NEWMAN and M. RYAN

Technical methods

A method for permanent preservation of antigenantibody precipitation lines in agar J. G. P. HUTCHISON

A micro method for agar-gel precipitin reactions $\mathcal{N}$ J. ROBERT MAY and G. A. RAWLINS

A method for obtaining concentrates of eosinophils from blood R. F. ALEXANDER and A. I. SPRIGGS

Technical notes on performing leucocyte counts onco the EEL blood cell counter J. G. SELWYN

An easy method to determine the serotonin content. of human platelets P. F. CROSTI and P. E. LUCCHELLI Book reviews

Copies are still available and may be obtained from the PUBLISHING MANAGER, BRITISH MEDICAL ASSOCIATION, TAVISTOCK SQUARE, W.C.1, price 17s. 6D. 